\title{
Growth and longevity in fishes of the family Scaridae
}

\author{
J. H. Choat*, L. M. Axe, D. C. Lou \\ Department of Marine Biology, James Cook University, Townsville, Queensland 4811, Australia
}

\begin{abstract}
Systematic check-marks in the sagittal otoliths from 6 species of scarids sampled from the Great Barrier Reef, Australia, were used to develop size-at-age plots. The species were Chlorurus gibbus, C. sordidus, Scarus frenatus, S. niger. S. psittacus and S. nvulatus. Comparative information for a seventh species, $S$. schelgeli, for which otolith increment data were avallable, was also included. Systematic check-marks in the form of alternating opaque and translucent bands were observed in the sectioned sagittae of all species. Regression of numbers of sagittal increments on sagittal weights revealed consistent linear relationships between these variables indicating continuous growth in sagittal thickness over the life span. For $C$. sordidus, $S$. frenatus, S. niger and $S$. rivulatus recapture of specimens injected with tetracycline confirmed an annual pattern in increment formation, with an opaque band being formed in early summer. Additional confirmation of the annual formation of opaque increments in $S$. rivulatus was obtained by margınal increment analysis. Size-at-age plots identified variable growth patterns and longevities among the 7 species. Growth in C. gubbus, S. psittacus, S. schelgeli and $S$. rivulatus was continuous with little evidence of an asvmptotic size. Life spans ranged from 5 yr $(S$. psittacus) to $14 \mathrm{yr}$ (C. gubbus). In C. sordidus, S. frenatus and S. niger there were clear asymptotic sizes achieved early in life and greater longevities (10 to $20 \mathrm{yr}$ ). All species were protogynous with evidence of sex-specific growth patterns. Transition to the terminal male identity was associated with enhanced growth resulting in larger and younger terminal males than females of equivalent size.
\end{abstract}

KEY WORDS: Scarid fishes - Growth Longevity Protogyny - Otolith increments - Valudation

\section{INTRODUCTION}

This study examines the growth patterns and life spans of a number of species of the family Scaridae, a group of fishes characteristic of coral reefs (Choat 1991). Although there are relatively few species $(80$ within 10 genera) (Bellwood 1994), they are a dominant group in terms of numbers and biomass in sha]low reef environments (Williams \& Hatcher 1983, Russ 1984, Choat \& Bellwood 1991). Among scarid species adult sizes vary from 110 to $1000 \mathrm{~mm}$ standard length (SL) although the majority lie within the range 200 to $500 \mathrm{~mm}$ SL. Estimates of growth rates and life spans are an important initial step in the investigation of productivity and turnover rates of these dominant coral reef fishes, which are heavily fished in some areas (Wright 1993). Scarids share a number of ecological traits and habitats with acanthurid fishes although the

-E-mail: john.choat@jcu edu.au
2 groups are phylogenetically distinct (Greenwood et al. 1966, Winterbottom \& McLennan 1993, Bellwood 1994). Information on growth rates and life spans is available for acanthurid fishes (Choat \& Axe 1996. Hart \& Russ 1996) and provides the opportunity to compare demographic features of co-occurring groups of reef fishes such as scarids and acanthurids from different phylogenetic backgrounds.

A number of studies have reported estimates of growth rates in scarids (Russ \& St. John 1988) and have identified variation in growth attributable to both habitat differences (Clifton 1995) and sexual identity (Warner \& Downs 1977, van Rooij et al. 1995). Warner \& Downs (1977) also estimated longevity and age structure in a Caribbean scarid based on alternating light and dark bands in skeletal elements assumed to be growth check-marks. There have been few attempts to extend this approach. Lou (1992) validated the annual nature of growth check-marks in sectioned sagittae from Scarus schlegeli Bleeker by tetracycline marking and marginal increment analysis. 
Confirmation of interpretable check-marks in otoliths from a variety of coral reef tishes, including scarids, has been reported by Fowler (1995). This study extends the number of scarid species for which sagittal check-marks have been recorded and validates their annual periodicity for an additional 4 species. The primary purpose of our study was to describe growth patterns using size-at-age relationships and to obtain estimates of longevities from a range of Indo-Pacific species.

\section{MATERIAL AND METHODS}

Study species and localities. Validated estimates of age from sagittal increments were obtained from Chlorurus sordidus Forsskal, Scarus frenatus Lacepede, S. niger Forsskal and S, rivulatus Valenciennes using sectioned sagittae. Two additional species, $C$. gibbus and S. psittacus were examined for patterns of sagittal increments. Comparative growth curves and otolith data are also provided for $S$. schelgeli, a species for which sagittal annuli have been previously validated (Lou 1992). Specimens of C. gibbus from Australian waters have been recently identified as $C$. microrhinos (Bleeker) but there appears to be no published opinion justifying this change.

The species studied covered a range of sizes, habitat associations and sexual ontogenies (Choat \& Randall 1986). All are protogynous hermaphrodites with either a monandric or diandric mode of sexual development (Choat \& Robertson 1975). Size ranges, sample sizes, and length-weight relationships are given in Table 1.

The majority of individuals of these species were collected from reefs surrounding Lizard Island, Australia, $\left(14^{\circ} 40^{\prime} \mathrm{S}, 145^{\circ} 28^{\prime} \mathrm{E}\right)$ with a small number being collected from adjacent mid-shelf reefs. Collections of $C$. gibbus were also made on fronts and passes of the

Table 1. Chlorurus gibbus, $C$ sordidus, Scarus frenatus, $S$ niger, S. psittacus, S. rivulatus, S. schlegeli. Length-weight relationships and size ranges of sampled individuals used in this study. For each species estimates of the parameters $a$ and $b$ for the relationship $W=a L^{b}$, coefficients of determination $\left(r^{2}\right)$ and the sample size $(n)$ are provided. Unit of weight is grams

\begin{tabular}{|lrccrr|}
\hline Species & $a \times 10^{5}$ & $b$ & $\mathrm{r}^{2}$ & $\mathrm{n}$ & $\begin{array}{c}\text { Size range } \\
\text { (mm) }\end{array}$ \\
\hline Chlorurus gibbus & 9.25 & 2.85 & 0.974 & 85 & $105-499$ \\
Chlorurus sordidus & 1.82 & 3.15 & 0.990 & 67 & $77-224$ \\
Scarus frenatus & 2.79 & 3.06 & 0.990 & 45 & $106-295$ \\
Scarus niger & 2.57 & 3.09 & 0.993 & 60 & $112-278$ \\
Scarus psittacus & 6.08 & 2.90 & 0.981 & 40 & $104-193$ \\
Scarus rivulatus & 1.73 & 3.14 & 0.982 & 374 & $18-290$ \\
Scarus schlegeli & 1.86 & 3.12 & 0.992 & 384 & $22-248$ \\
& & & & & \\
\hline
\end{tabular}

Outer Barrier Reefs (Hicks, Day and No Name Reefs) 15 to $25 \mathrm{~km}$ northeast of Lizard Island. Individuals of all species were selectively collected by spearing or by $1.5 \times 30 \mathrm{~m}$ drive nets on reef crests and slopes.

The purpose of selective sampling was to collect the largest individuals for estimates of maximum ages, and to provide coverage of the full size range for construction of size-at-age plots. Choat \& Bellwood (1985) provided information on the depth distribution and habitat associations of scarid species in the study area. This allowed us to locate and sample the largest individuals of each species. Sampling was not designed to provide representative estimates of each age group and small individuals (<80 mm SL) in particular were not adequately sampled.

Tagging and otolith processing. We validated otolith increments by tagging, tetracycline injection and recapture of individuals of Chlorurus sordidus, Scarus frenatus, S. rivulatus and S. niger Fish were collected for tagging by the use of $1.5 \times 30 \mathrm{~m}$ drive nets $150 \mathrm{~mm}$ mesh), measured to the nearest $\mathrm{mm}$ for standard length and fork length, and tagged immediately on site. Individually numbered T-bar anchor tags were inserted between the dorsal pterygiophores. Each fish was injected in the visceral cavity with a solution of oxytetracycline and saline with a dosage of $50 \mathrm{mg} \mathrm{kg}^{-1}$ body weight (McFarlane \& Beamish 1987) with the dosage converted to length of fish based on the lengthweight relationships shown in Table 1 . The main tagging program was carried out at Lizard Island in November 1991 and February 1992 although a small number of scarids were tagged at Lizard Island in 1989. In addition, specimens of $C$. sordidus, $S$. frenatus, and $S$ niger were injected with tetracycline, placed in an outdoor aquarium and the sectioned sagittae examined for annuli after 1 yr. Validation of sagittal increments in $S$. schelgeli has been described previously (Lou 1992).

No validations were obtained for Chlorurus gibbus and Scarus psittacus. Although both species showed clearly defined increments, in the present study we simply assumed an annual banding of opaque regions in the sagittae.

Fish collected for otolith analysis were placed on ice and processed in the laboratory on the same day. Standard and fork lengths were measured to the nearest millimetre and weight was measured to the nearest gram. For each individual both sagittae and lapillae were removed, cleaned in distilled water and stored dry after washing with ethanol.

Most individuals of Scarus rivulatus were collected during an earlier study on scarid growth (Lou 1992). Collections of $S$. rivulatus were made at $6 \mathrm{wk}$ intervals during 1989 and 1990 from fringing reef surrounding Lizard Island. These samples provided the means for 
marginal increment analysis which involved examination of the dorsal side of the sectioned sagittal sulcus to determine whether it was opaque or translucent. The percentage of fish with opaque otolith margins was calculated for each sample.

Only sagittae were used for aging purposes. One from each pair was weighed to the nearest $0.1 \mathrm{mg}$. This was embedded in epoxy resin, sectioned transversely at 300 to $500 \mu \mathrm{m}$ through the core using a low speed Buehler isomet saw and ground using 600,800 and 1200 grit abrasive paper. Otolith sections were mounted on a glass slide with thermoplastic glue (Crystallbond) and polished using $0.3 \mu \mathrm{m}$ alpha alumina powder and a polishing cloth.

Sectioned otoliths were examined under both high power and dissecting microscopes using transmitted light. Each otolith was examined and read at 3 different times for incremental bands representing annuli. Counts of increments were made along a consistent track (Choat \& Axe 1996).

Analysis. Von Bertalanffy growth functions provided the best empirical fit to estimates of size-at-age in all species with the exception of Scarus rivulatus. The equation $L_{t}=L_{\infty}\left(1-\mathrm{e}^{-K_{i t}-t_{i}}\right)$ was fitted to the size-atage data where $L_{l}$ is the mean length at age $t_{\text {, }}$ and $L_{\infty}$ is the asymptotic mean length. For $S$. rivulatus the best empirical description was obtained by fitting the equation $\log Y=\log a+b \cdot \log X$ to the size-at-age data. The relationship between otolith weight and annulus number was examined by least squares regression analysis with sagittal weight as the independent variable. All values for size are standard length ( $\mathrm{mm}$ ).

\section{RESULTS}

\section{Otolith structure and validation}

The 7 species investigated showed a considerable range of lengths and body mass (Table 1). For the smallest species, Scarus psittacus, the largest terminal male weighed $270 \mathrm{~g}$. For Chlorurus gibbus the largest terminal male weighed $5000 \mathrm{~g}$. Length-weight relationships for the 7 species examined displayed predictable values ( $b$ ranging from 2.85 to 3.15 ) when the equation $W=a L^{b}$, where $W$ was the weight and $L$ was standard length, was fitted (Table 1). The $r^{2}$ values ranged from 0.974 to 0.993 .

When viewed in transverse section, sagittae of Chlorurus gibbus, C. sordidus, Scarus frenatus, S. niger, $S$ psittacus and $S$. rivulatus showed interpretable, regular increments or banding patterns with opaque bands alternating with translucent bands (Fig. 1). Compared with acanthurids, scarids showed a relatively small number of sagittal increments, with a maximum of 20 as opposed to numbers consistently greater than 40 increments in Naso spp. and Prionurus maculatus (Choat \& Axe 1996). Sagittal mass in scarids and acanthurids is similar (Choat \& Axe 1996, see Fig. 4 this study). Consequently the opaque bands in scarid sagittae are widely spaced and provide an opportunity for marginal increment analysis (Lou 1992)

Returns on tagging for scarids were very poor. In an earlier cycle of tagging in 1989 and 1990, 62 individuals of Scarus schelgeli and 30 of S. rivulatus were tagged and injected at one site. One individual of each species was recovered after 12 mo. In each species a single tagged individual was observed at the tagging site after 12 mo but not recaptured. Significantly, surveys of the tagging sites after 2 wk revealed very few $S$. schelgeli and $S$, rivulatus compared to the large numbers of tagged acanthurids which were processed at the same time. We suggest that scarids are more prone to stress reactions following tagging. Large numbers of muraenid eels were present at the main tagging site (Granite Bluffs, Lizard Island) and may have located recently tagged scarids in their sleeping sites

Only small numbers of Chlorurus sordidus, Scarus frenatus and $S$. niger $(8,25$ and 24 , respectively) were tagged. For these species, tagging was carried out in February 1992 on the exposed southeast reef face of Lizard Island. Small, but proportionately better, returns (1, 3 and 2 individuals, respectively) were obtained. For each of these species and S. rivulatus (tagged March 1990) a single individual with a clear tetracycline band in the sagittal sections was obtained

Information on timing of opaque band formation relative to the tetracycline marks and the sizes at tagging and recapture is given in Fig. 2. In all species the tetracycline mark (February-March) was adjacent to the outer margin of an opaque band. For Chlorurus sordidus and Scarus niger recaptured 11 mo after tagging there was a single opaque band at the outer margin. For $S$. frenatus and $S$. rivulatus there were 2 and 3 opaque bands with time at liberty being 21 and 34 mo, respectively. Our interpretation is that a single opaque band is laid down each year in spring-early summer which is consistent with the pattern seen in a number of coral reef fishes (Fowler 1995). Individuals recaptured in January showed an opaque band near the outer margin of the sagittae followed by a smaller translucent area

The demonstration of the periodicity of opaque band formation is consistent with the information provided by Lou (1992) for Chlorurus sordidus, Scarus frenatus and $S$. niger Individuals of $C$. sordidus and $S$. frenatus tetracycline-injected and maintained in an outdoor aquarium for up to 3 yr showed opaque bands consistent with the assumption of annual formation. For $S$ niger, an individual at liberty in the field for $13 \mathrm{mo}$ showed a single opaque band (Lou 1992). 

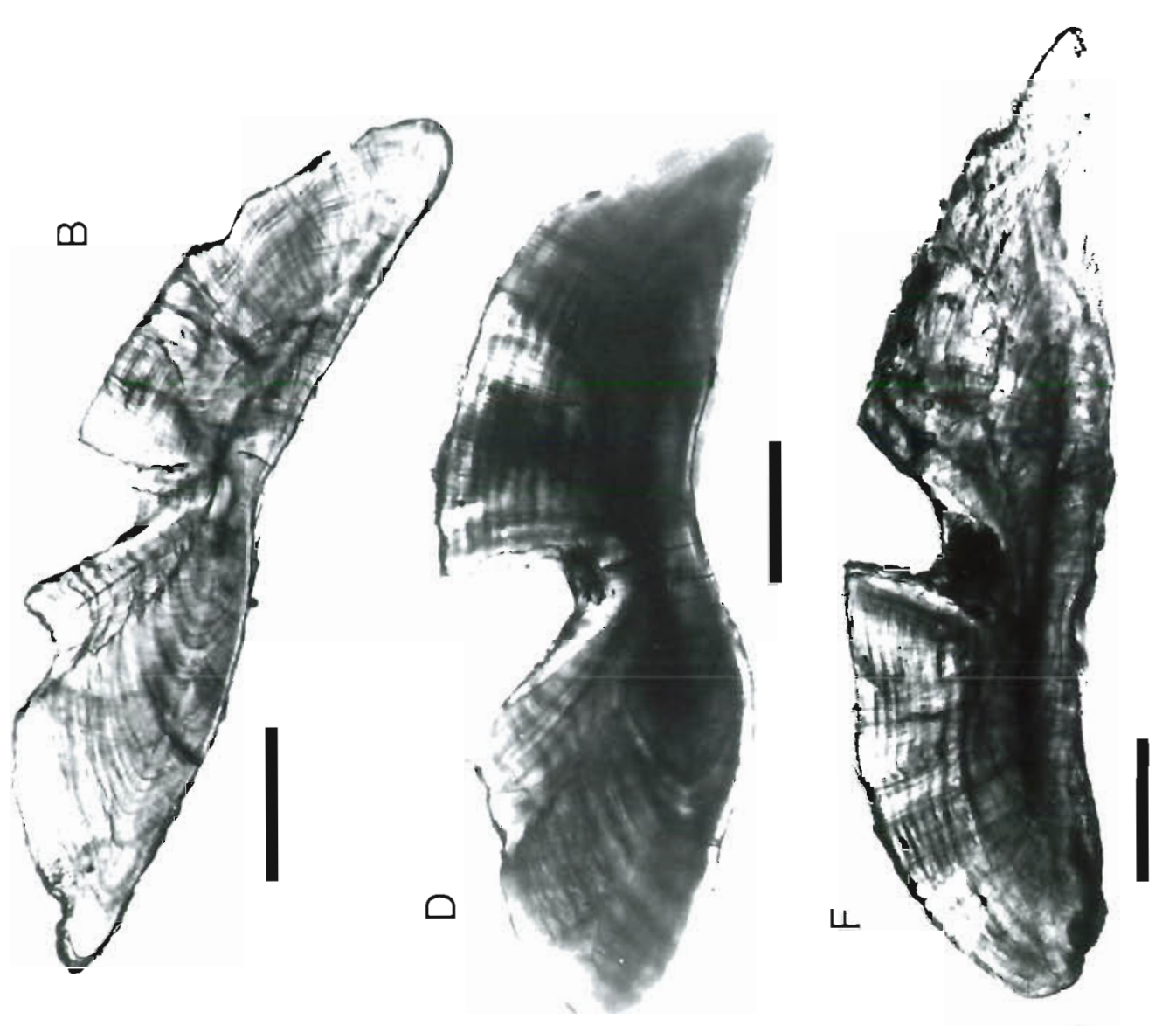

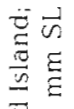

可范

$\stackrel{3}{a}$

这

눙

E.

可

部

E

80

的牙

可

经

苛范

ब.

可

出

量

ड्ते है

워

फ)
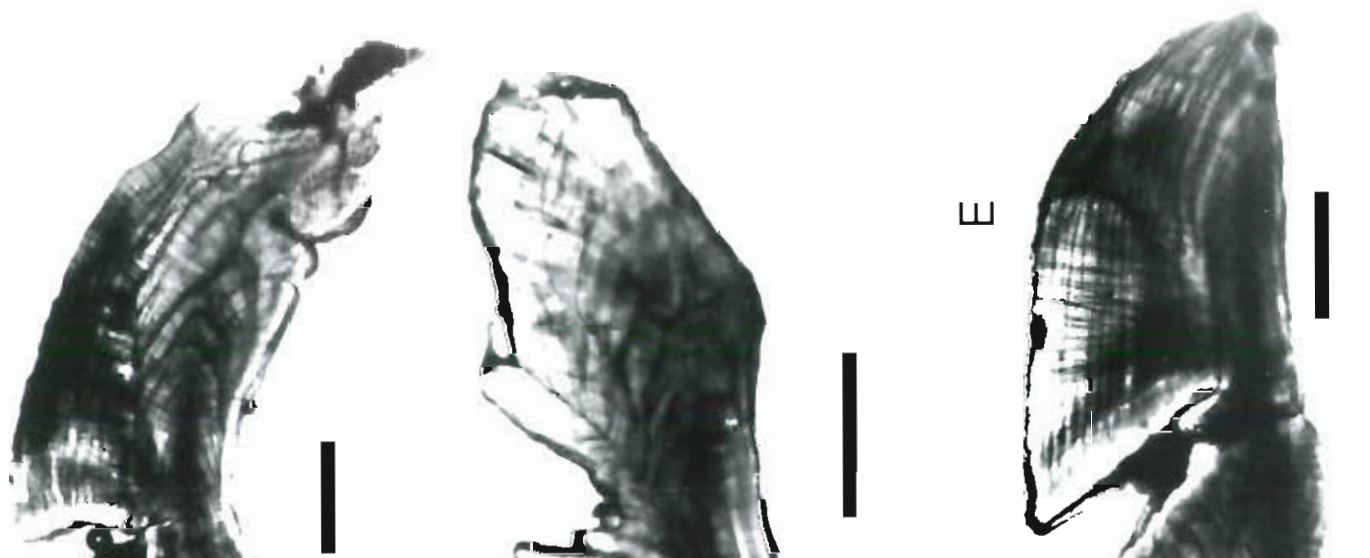

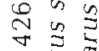

is $\Xi \begin{gathered} \\ 0\end{gathered}$

50

绳范

它鸪

这证

可

离

동

용

焉富

高是

in

过

政

苛

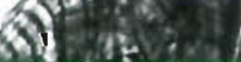

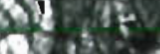

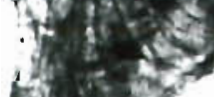

Ha 5

32.

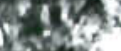

(a) $<$

$\leftarrow$

৩

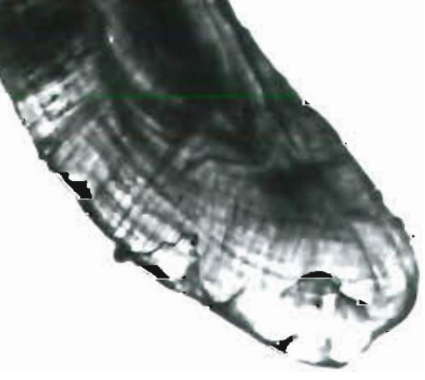

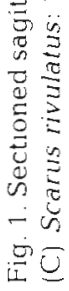


Chlorurus sordidus

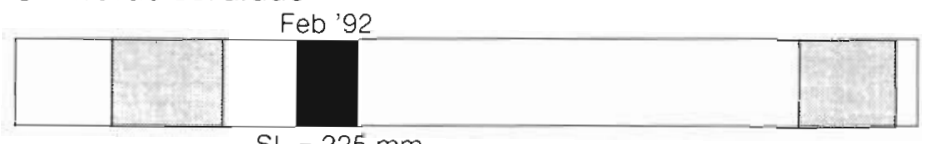

$\mathrm{SL}=225 \mathrm{~mm}$

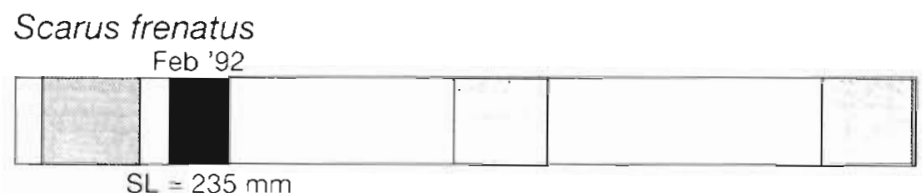

$\mathrm{SL}=235 \mathrm{~mm}$
Jan' 93

$\mathrm{SL}=224 \mathrm{~mm}$

Age $=6$

Nov'g3

$\mathrm{SL}=242 \mathrm{~mm}$

Age $=12$
Fig. 2. Chlorurus sordidus, Scarus frenatus, S. niger, S. rivulatus. Diagrammatic sequence of opaque and translucent increments in the sagittae from individuals recovered after tetracycline treatments. Diagrams show relative positions of tetracycline bands, increments and the otolith margin at time of recovery. $S$. niger does not display a terminal phase. Dates represent time of tagging (top of each bar) and time of recovery (end of each bar). SL is standard length at time of tagging and time of recovery. Age is the estimate (in yr) at recovery date

\section{Scarus niger}

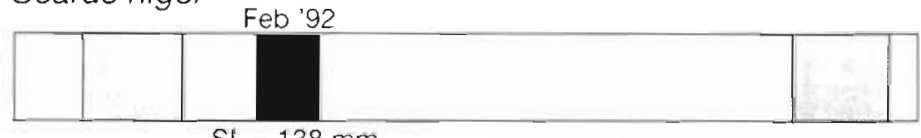

$\mathrm{SL}=138 \mathrm{~mm}$

Jan' 93

$\mathrm{SL}=166 \mathrm{~mm}$

Age $=2$

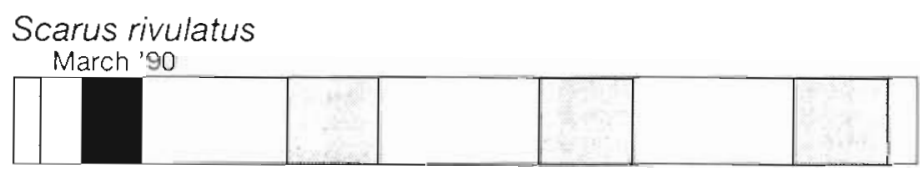

$\mathrm{SL}=161 \mathrm{~mm}$

Jan '93

$\mathrm{SL}=192 \mathrm{~mm}$

Age $=5$

Translucent zone

Tetracycline mark
An independent validation of annual formation of opaque increments was achieved by marginal increment analysis of otoliths of Scarus rivulatus. The results suggest that by December in a given year the majority of individuals have an opaque sagittal margin and confirms the suggestion of a single annual opaque band formed in spring (Fig 3).

For all species there was a significant positive linear relationship between estimated age in years (number of opaque bands) and sagittal weight as shown by fitting least-squares regressions to the data (Fig. 4). with an asymptotic size established relatively early in life. The 4 continuously growing species had relatively short life spans although $C$. gibbus reached 15 yr The three species forming the second grouping were relatively long-lived with life spans between 10 and 20 yr. There was no consistent relationship between growth patterns and body size.

Size-at-age relationships were adequately described by Von Bertalanffy growth functions with the exception of Scarus rivulatus (Fig. 5, Table 2). For this species there was considerable variation in size in the

Sagittae show a continuous linear increase in weight over the lifetime of the fish. The variability in some of the data-sets was substantial, indicating both the possibility of errors in increment estimates and variability in otolith growth and internal structure.

\section{Size-at-age}

Size-at-age data plotted for each species revealed variable patterns of growth and longevity (Fig. 5). These could be partitioned into 2 groups of species. Chlorurus gibbus, Scarus psittacus, S. schelgeli and S. rivulatus showed continuous growth over the age classes sampled. This group contained both the largest and the smallest species examined. The second group C. sordidus, S. frenatus and $S$. niger showed determinate growth

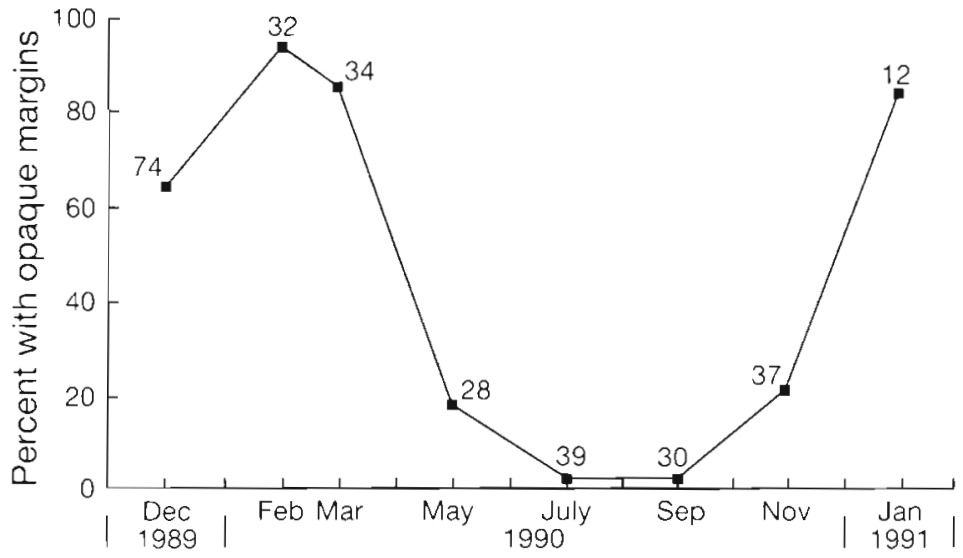

Fig. 3. Marginal increment analysis for sagittae of Scarus rivulatus collected at approximately 6 wk intervals from December 1989 to January 1991. Y-axis is the percentage of sectuoned sagittae in which the outer margin is occupied by an opaque band. Sample sizes shown for each collecting period 

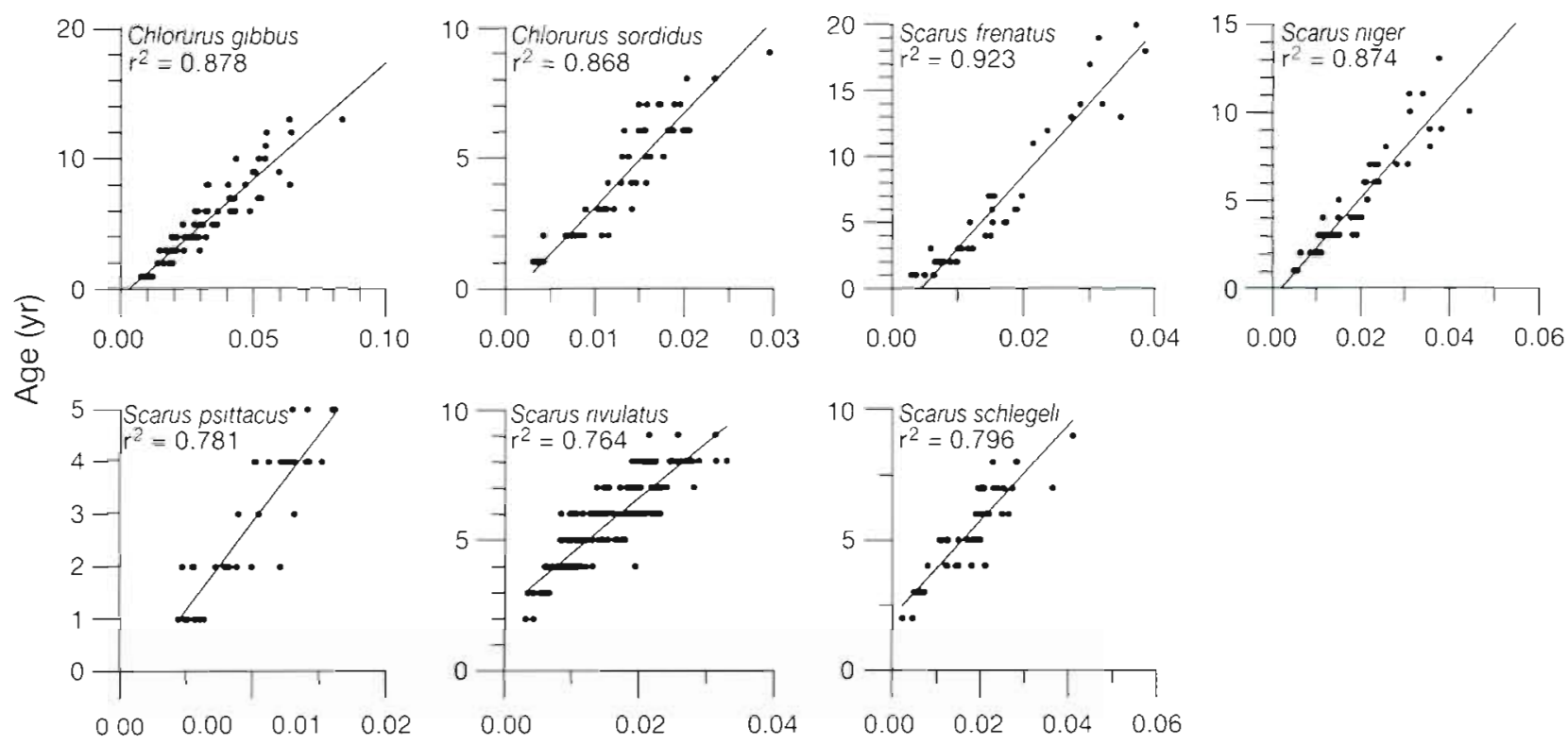

Sagittal weight $(\mathrm{g})$

Fig. 4. Least-squares linear regressions of sagittal increments (age) on sagittal weight. Chlorurus gibbus: $y=-0.453+177.999 x$ $(\mathrm{n}=83)$ : C. sordidus: $y=-0.479+356.105 x(\mathrm{n}=62) ;$ Scarus frenatus: $y=-2.357+547.171 x(\mathrm{n}=41) ;$ S. niger: $y=-0.503+280.445 x$ $(\mathrm{n}=58) ;$ S. psittacus: $y=-0.447+331.650 x(\mathrm{n}=61) ;$ S. rivulatus: $y=2.410+208.423 x(\mathrm{n}=193) ;$ S. schlegeli: $y=2.091+182.181 x$ $(n=50)$

older age classes. Similar variability was observed in other species, particularly Chlorurus gibbus and $C$. sordidus, All of the study species were protogynous hermaphrodites (Choat \& Randall 1986) with terminal males concentrated in the upper size classes
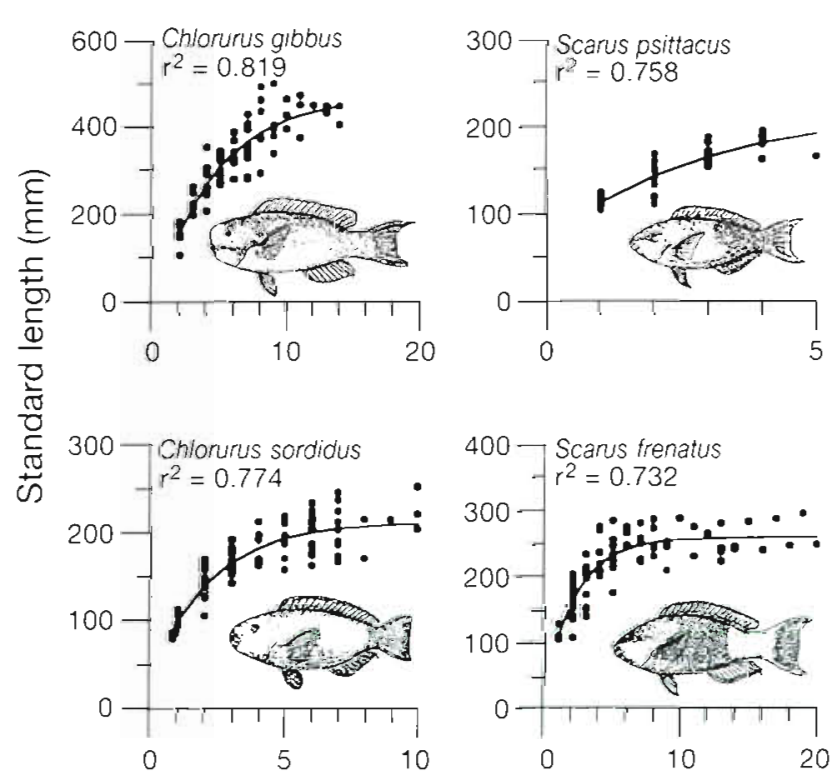

The size-at-age plots for each species were partitioned by sexual identity: among females, initial-phase males and terminal males in the diandric species, and among females and terminal males in the monandric examples. For the diandric scarids Scarus schelgeli and
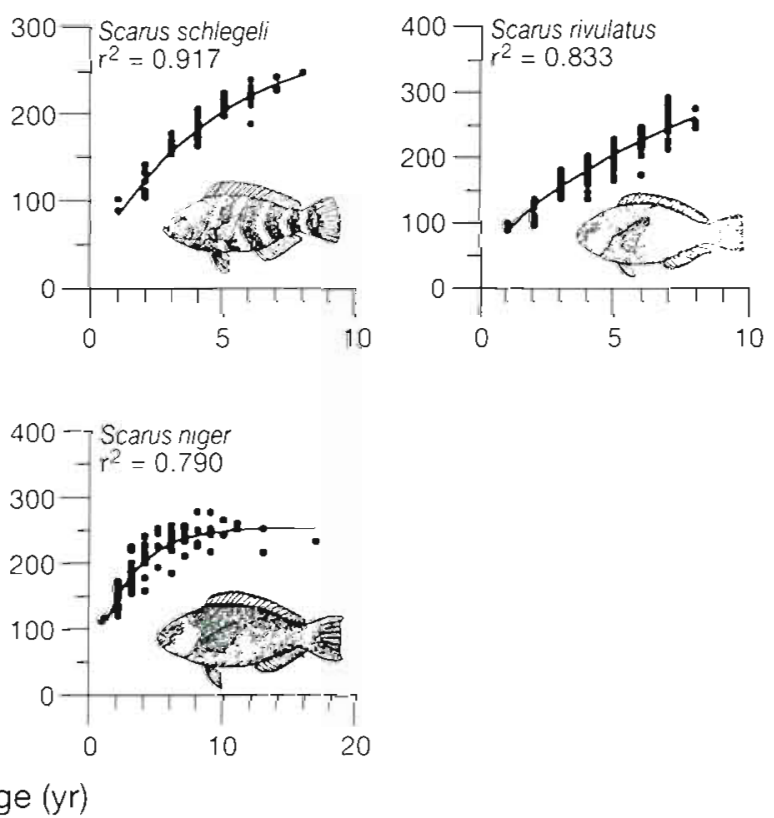

Fig. 5. Chlorurus gibbus, Scarus psittacus, S. schlegeli, S. rivulatus, C. sordidus, S. frenatus, S. niger. Relationshup between size (SL) and age. For S. rivulatus, data are fitted to the equation $Y=a X^{b}$ For the other species, data are fitted to the Von Bertalanffy equation $L_{i}=L_{\infty}\left(1-\mathrm{e}^{-k^{\prime}\left(t-t_{0}\right)}\right)$ 
Table 2. Parameter values for size-at-age plots (Fig. 5). Values are Von Bertalanffy parameters $\left(L_{\ldots}, K, t_{0}\right)$, coefficients of determination $\left(\mathrm{r}^{2}\right)$, and sample sizes for Chlorurus gibbus, Scarus psittacus, S. schlegeli, C. sordidus, S. frenatus and S. niger. For $S$. nvulatus the parameters are for $Y=a X^{b}$

\begin{tabular}{|lccrc|}
\hline Species & $L_{\infty}(\mathrm{mm})$ & $K$ & \multicolumn{1}{c}{$t_{0}$} & $\mathrm{n}$ \\
\hline Chlorurus gibbus & 465.23 & 0.225 & 0.186 & 82 \\
Scarus psittacus & 214.85 & 0.347 & -1.122 & 40 \\
Scarus schlegeli & 287.88 & 0.224 & -0.526 & 50 \\
Chlorurus sordidus & 211.21 & 0.452 & -0.410 & 83 \\
Scarus frenatus & 259.00 & 0.448 & 0.276 & 78 \\
Scarus niger & 253.67 & 0.367 & -0.480 & 74 \\
& & $b$ & & $\mathrm{n}$ \\
Scarus rivulatus & 86.88 & 0.530 & & 188 \\
& & & & \\
\hline
\end{tabular}

S. rivulatus, sufficient initial-phase males were collected to compare them with females. Size-at-age relationships among these 2 sexual identities were similar (Fig. 6). However, terminal-phase males were larger than male and female initial-phase individuals of the same age (Fig 6). The monandric species Chlorurus gibbus, $C$. sordidus, $S$. frenatus and $S$. niger showed a similar pattern with secondary males being consistently larger than females of the same age (Fig. 6).

These size-at-age relationships partitioned by sexual identity were also adequately described by Von Bertalanffy growth functions (Fig. 6) which emphasise the differences between terminal- and initial-phase fish. These differences were very conspicuous in the longer lived species and contributed to the variation in the size-at-age plots. In some species (Scarus frenatus) females occupied the full range of age classes sampled, thus suggesting that some individuals retain the female identity for life.

\section{DISCUSSION}

The material described here confirms the presence and utility of annual check-marks in the skeletal structures of scarids (Warner \& Downs 1977, Lou 1992, Fowler 1995). In the general case such increments provide an important basis for describing growth patterns and other age-specific properties of reef fish life histories. For sex-reversing species such as scarids they provide an additional perspective on life history events associated with a protogynous pattern of sexual development. In this study we were able to describe agespecific life history events in both monandric and diandric scarids

In comparison with co-occurring acanthurids maximum life spans were shorter and more variable, ranging from 5 to $20 \mathrm{yr}$. The longest lived scarid in this study, Scarus frenatus, achieved 20 yr maximum, equivalent to that of Acanthurus nigrofuscus, one of the smallest and shortest lived acanthurids for which age has been validated (Hart \& Russ 1996). There are few estimates of scarid maximum age available from the literature. Warner \& Downs (1977) suggest a maxi-
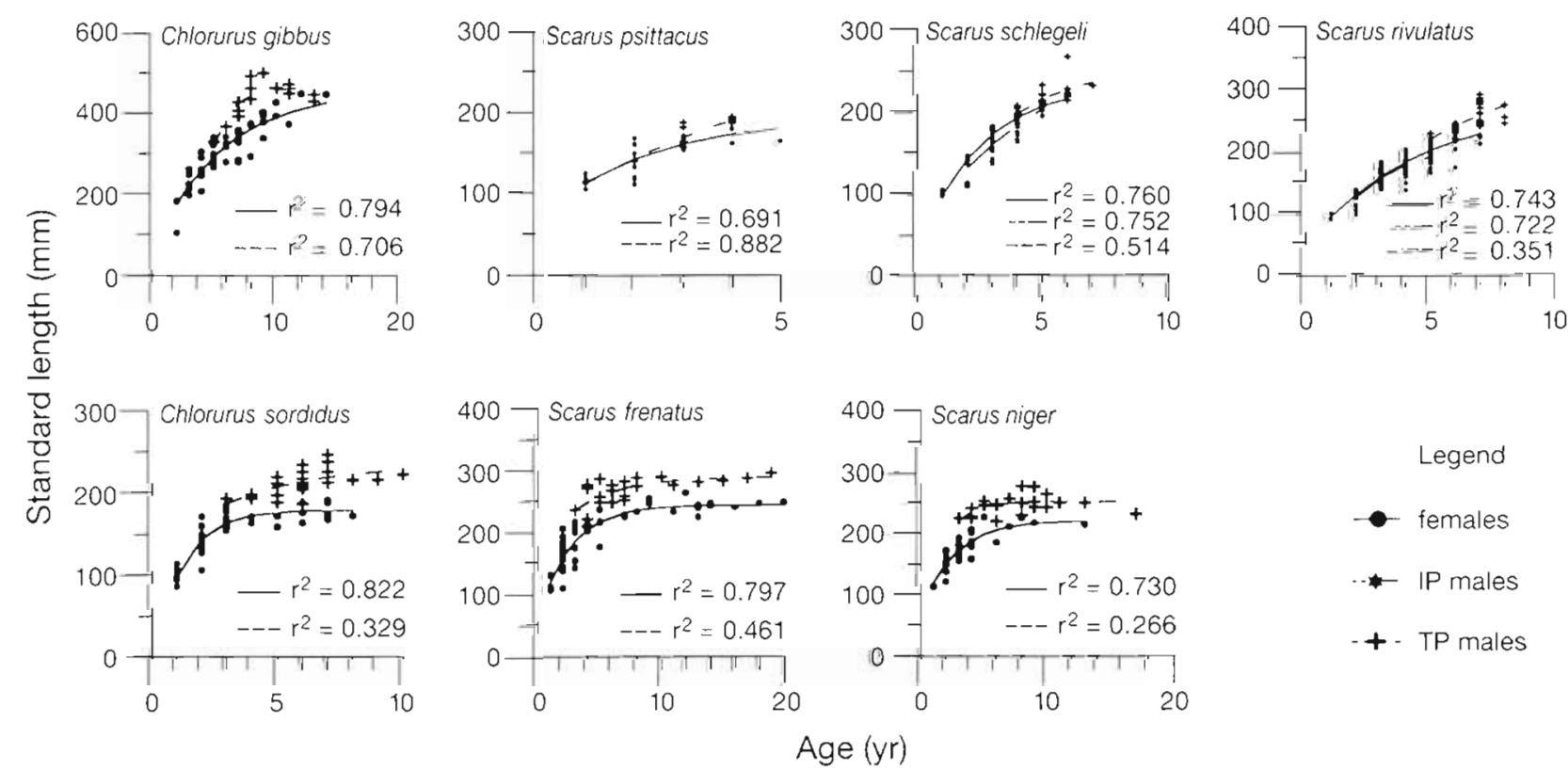

Fig. 6. Chlorurus gibbus, Scarus psittacus, S. schlegeli, S. nvulatus, C. sordidus, S. frenatus, S. niger. Relationship between size (SL) and age for sexual identities. Data are fitted to the Von Bertalanffy equation $L_{l}=L_{\infty}\left(1-e^{-k i t-t_{i}}\right)$. For the diandric species S. schelgeli and S. rivulatus, sufficient initial-phase males were collected to fit equations to both initial-phase males and females and terminal males. For remaining species, equations are fitted to females and terminal males 
mum age of 6 yr for Scarus iserti, which is similar to estimates for short-lived species from this study. van Rooij et al. (1995) provide growth curves for the larger Caribbean species Sparisoma viride, but it is not possible to estimate life spans from their mark-recapture data

Size-at-age plots for Chlorurus sordidus, Scarus frenatus and $S$. niger showed evidence of asymptotic growth. For $S$ frenatus many age classes accumulated in the 220 to $260 \mathrm{~mm}$ SL size range. All 3 species, especially $S$. frenatus and $S$. niger are relatively rare in the study area (Choat \& Bellwood 1985) with a substantial degree of site attachment and a monandric mode of sexual ontogeny. In contrast, C. gibbus, S. psittacus, $S$. rivulatus and $S$. schelgeli were mobile schooling species with the latter 3 achieving high abundances in the study area. Growth was continuous over the ranges investigated with little evidence of reduced growth rates in larger individuals.

Protogynous coral reef fishes are characterised by a differential investment in gonad tissue. Gonads of terminal male scarids are usually much smaller than those of females and primary males (Robertson \& Warner 1978 ) and this may be associated with different growth patterns amongst the sexes (van Rooij et al. 1995). Analysis of sex-specific growth patterns in this study established that terminal males were consistently larger than females for a given age class. For the abundant diandric species (S. psittacus, $S$. schelgeli and $S$. rivulatus), overlap among initial phase and terminal phase was relatively small. Terminal-phase fishes dominated the older age classes but did not persist in the population. Sexual transition was associated with enhanced growth but post-transition life spans were relatively short.

Chlorurus sordidus, Scarus frenatus and S. niger showed different demographic characteristics. Sex transition occurred early in the life span of these longer lived species and was also associated with enhanced growth. However, the age data shows that some females persisted into the older age classes. Achievement of asymptotic size and the appearance of terminal males occurred at a similar age, 3 to 4 yr in each species. The size-at-age plots generated distinctive sex-specific patterns in which terminal males maintained larger sizes in each age class over the recorded life spans.

The distribution of sexual identities in protogynous fishes is usually analysed in terms of fish length. This produces the characteristic 'protogynous' pattern (Sadovy \& Shapiro 1987) with the distribution of terminal males concentrated in the larger size classes. This was the case for Chlorurus sordidus, Scarus frenatus and $S$. niger where terminal males were consistently larger than females. These distributions tend to rein- force the assumption of young females and old terminal males with uniform growth rates among the sexes.

Examining the distribution of sex by age in this group of species provides a different demographic perspective. Males are present in most mature age classes. Females and males are equally long-lived suggesting that some females will retain the same sexual identity throughout life. This distribution is driven by the different growth rates between females and terminal males with an important factor being enhanced growth following sexual transition.

The primary purpose of this study was to assemble information on age structure and longevity in scarids through size-at-age relationships. These are modified by both sex-and locality-specific influences on growth rate. Our findings suggest substantial changes to growth patterns associated with sexual identity. The differences may be more dependent on behavioural interactions and local habitat features than we have suggested (Warner \& Downs 1977, Clifton 1995, van Rooij et al. 1995). Differences in growth rates and longevity associated with environmental gradients are under investigation.

Acknowledgements. The study was supported by an ARC grant to J.H.C. A tagging pilot study was supported by an ARC grant to J.H.C., G. R. Russ and D. Williams. Facilities and logistic support were provided by the Lizard Island Research Station and the Australian Museum. Laboratory work and access to aquanum facilities were supported by the James Cook University internal grant system. Assistance with the tagging and sampling program was provided by $\mathrm{B}$. Kerrigan, B. Ferreira, K. Clements, D. Wilson, W. Robbins, D. Welsh and $S$. Purcell. This work benefited from discussions with G. Russ, D. Bellwood, K. Clements, P. Doherty and D. Williams. N. Moltschaniwskyj provided advice with data analysis. Original drawings were by Lucy Smith.

\section{LITERATURE CITED}

Bellwood DR (1994) A phylogenetic study of the parrotfishes family Scaridae (Pisces: Labroidei), with a revision of genera. Records of the Australian Museum Supplement No. 20:1-84

Choat JH (1991) The biology of herbivorous fishes on coral reefs. In: Sale PF (ed) The ecology of fishes on coral reefs. Academic Press, San Diego, CA. p 120-155

Choat JH, Axe LM (1996) Growth and longevity in acanthurid fishes; an analysis of otolith increments. Mar Ecol Prog Ser $134: 15-26$

Choat JH, Bellwood DR (1985) Interactions amongst herbivorous fishes on a coral reef influence of spatial variation. Mar Biol 89:221-234

Choat JH, Bellwood DR (1991) Reef fishes: their history and evolution. In: Sale PF (ed) The ecology of fishes on coral reefs. Academic Press, San Diego, CA, p 39-66

Choat JH, Randall JE (1986) A review of the parrotfishes (Family Scaridae) of the Great Barrier Reef of Australia with descruption of a new species. Records of the Australian Museum 38:175-228 
Choat JH, Robertson DR (1975) Protogynous hermaphroditism in fishes of the Family Scaridae. In: Reinboth R (ed) Intersexuality in the animal kingdom. Springer-Verlag, Heidelberg, p 263-283

Clifton KE (1995) Asynchronous food availability on neighbouring Caribbean coral reefs determines seasonal patterns of growth and reproduction for the herbivorous parrotfish Scarus iserti. Mar Ecol Prog Ser 116:39-46

Fowler AJ (1995) Annulus formation on otoliths of coral reef fish - a review. In: Secor DH, Dean JM, Campana SE (eds) Recent developments in fish otolith research. University of South Carolina Press, Columbia, p 45-63

Greenwood PH, Rosen SH, Weitzman SH, Myers CS (1966) Phyletic studies of teleostean fishes, with a provisional classification of living forms. Bull Am Mus Nat Hist 131 $339-456$

Hart AM, Russ GR (1996) Response of herbivorous fish to crown-of-thorns starfish Acanthaster planci outbreaks. III. Age, growth, mortality and maturity indices of Acanthurus nigrofuscus. Mar Ecol Prog Ser 136:25-35

Lou DC (1992) Validation of annual growth bands on the otolith of tropical parrotfishes (Scarus schlegeli Bleeker). J Fish Biol 41:775-790

McFarlane GA, Beamish RJ (1987) Selection of dosages of oxytetracycline for age validation studies. Can $J$ Fish Aquat Sci 44:905-909

Robertson DR, Warner RR (1978) Sexual patterns in the labroid fishes of the western Caribbean. II: the parrot

This article was presented by G. F. Humphrey (Semior

Editorial Advisor), Sydney, Australia fishes (Scaridae). Smithson Contrib Zool 255:1-26

Russ GR (1984) Distribution and abundance of herbivorous grazing fishes in the central Great Barrier Reef. Il. Patterns of zonation of mid-shelf and outershelf reefs. Mar Ecol Prog Ser 20:35-44

Russ GR, St. John J (1988) Diets, growth rates and secondary production of herbivorous coral reef fishes. Proc 6th Int Coral Reef Cong 2:37-43

Sadovy Y, Sharpiro DY (1987) Criteria for the diagnosis of hermaphroditism in fishes. Copeia 1987:136-156

van Rooij JM, Bruggemann JH, Videler J山, Breeman AM (1995) Plastac growth of the herbivorous reef fish Sparisoma viride: field evidence for a trade-off between growth and reproduction. Mar Ecol Prog Ser 122:93-105

Warner RR, Downs IF (1977) Comparative life histories: growth vs reproduction in normal males and sex-changing hermaphrodites of the striped parrotfish, Scarus croicensis. Proc 3rd Int Coral Reef Symp 1:275-281

Williams DMcB, Hatcher AI (1983) Structure of fish communities on outer slopes of inshore, mid-shelf and outer shelf reefs of the Great Barrier Reef. Mar Ecol Prog Ser 10 $239-250$

Winterbottom R, McLennan DA (1993) Cladogram versatility evolution and biogeography of acanthuroid fishes. Evolution 47:1557-1571

Wright A (1993) Shallow water reef-associated finfish. In Wright A, Hill L (eds) Nearshore marine resources of the South Pacific. IPS, Suva, Fiji, p 203-284

Manuscript first received: April 26, 1996

Revised version accepted: September 9, 1996 